\title{
Association of treatment and outcomes of doctor-shopping behavior in patients with hepatocellular carcinoma
}

This article was published in the following Dove Press journal:

Patient Preference and Adherence

10 July 2013

Number of times this article has been viewed

\section{Cheng-I Hsieh ${ }^{1-3}$ \\ Kuo-Piao Chung ${ }^{3}$ \\ Ming-Chin Yang ${ }^{3}$ \\ Tsai-Chung Li ${ }^{4-6}$}

'Division of Hematology and Oncology, Department of Internal Medicine, Taipei Medical University Hospital, ${ }^{2}$ Department of Internal Medicine, School of Medicine, College of Medicine, Taipei Medical University, ${ }^{3}$ Institute of Health Policy and Management, College of Public Health, National Taiwan University, Taipei, ${ }^{4}$ Graduate Institute of Biostatistics, College of Public Health, China Medical University, ${ }^{5} \mathrm{Graduate}$ Institute of Chinese Medicine Science, College of Chinese Medicine, China Medical University, ${ }^{6}$ Department of Healthcare Administration, College of Health Science, Asia University, Taichung, Taiwan
Correspondence: Kuo-Piao Chung Room 635, 17 Suchow Rd, Taipei, Taiwan 10052, People's Republic of China Tel +886233668065

Fax 886223581541

Email kpchung@ntu.edu.tw
Background: A variety of unfulfilled needs may trigger doctor-shopping behavior (DSB) in patients. In oncology, treatment results usually cause patients the most concern. This study investigated the association of DSB with active treatments received by patients with hepatocellular carcinoma (HCC) and outcomes.

Methods: With approval from the institutional review board, all patients registered in the cancer database of a teaching hospital and diagnosed as having HCC by self-referral from outside hospitals or by in-house diagnosis were retrospectively identified. Patient data were then reviewed and analyzed via electronic medical records.

Results: Hepatitis B carriers were significantly more likely than noncarriers to show first-time DSB. Recurrent disease was less likely to result in DSB than predicted. Patients from outside hospitals not receiving upfront first treatment after diagnosis were significantly more likely to show more frequent DSB than those receiving it. Male patients eligible for salvage treatment were less likely to have frequent occurrences of DSB than their female counterparts. Receiving first salvage treatment was not associated with more frequent DSB. Treatment recommendations offered in the study hospital did not influence patients' decisions to leave or stay. Only elderly patients ( $>70$ years) were less likely to show DSB.

Conclusion: DSB can occur throughout the entire course of treatment for HCC for a variety of reasons. Active treatments, disease status, and patient characteristics all exerted an influence on DSB.

Keywords: doctor-shopping behavior, second opinion, hepatocellular carcinoma

\section{Introduction}

Physician-initiated second opinion (SO) and doctor-shopping behavior (DSB) are common phenomena in patients for various reasons. No prior research has differentiated DSB and SO, but both are recognized as behaviors of searching for information on diagnoses, treatment options, and outcomes, which may assist with the management of patients' own health. ${ }^{1}$ Although data on incidence rates are lacking, according to surveys, DSB occurs in all fields of medicine and has rapidly gained popularity. ${ }^{2,3}$ One series reported $16 \%$ of US patients as seeking a second medical opinion. ${ }^{4}$ In Europe, the field of elective surgery has initiated SO evaluations. ${ }^{5-8}$ Despite their significance, research on SO and DSB is limited, and may differ according to specialties, diseases, culture, and health systems.

In Taiwan, Western medicine was introduced by a missionary in 1865 . After World War II, Taiwan was ceded to Japan, and Western medicine was consolidated as a fundamental health care system from 1899 to 1936 . The traditional patient-physician 
relationship in Japan has often been described as hierarchical and paternalistic compared with Western countries. ${ }^{9,10}$ Japanese physicians usually do not discuss treatment options and the details of procedures with patients. ${ }^{11}$ Because of this background, Taiwanese patients always believed and trusted medical authority figures until the recent introduction of consumerism, informed consent, patient autonomy, and other concepts pertaining to human rights. This evolution may also increase DSB. In general, Taiwanese patients typically visit a physician or an outpatient department frequently. Many patients not only consult several physicians of different specialties at different health care facilities, but also switch them rapidly. ${ }^{12}$

Patients may consult other doctors for various reasons. Attributable patient factors include the patient's dissatisfaction with ${ }^{13-15}$ or distrust of ${ }^{14,16,17}$ a doctor, concerning the critical diagnosis, poor prognosis and difficult treatments, ${ }^{2,3,18}$ or the patient feeling insufficient time has been provided for discussion. ${ }^{19}$ Other factors include personal beliefs, religious dogma, ${ }^{20}$ the desire to be more informed, ${ }^{21}$ the patient's educational background, ${ }^{17}$ gender, ${ }^{1,22}$ health status, ${ }^{1,14,23}$ and hospital stay. ${ }^{14}$ Doctor factors that influence DSB include the doctor's professional knowledge and skills, ${ }^{24}$ personal characteristics (such as age and race), and attitudes. ${ }^{24,25}$ Other factors include traffic convenience, ${ }^{16,24}$ waiting time, ${ }^{24}$ verbal recommendations from others, ${ }^{26}$ reputation of an institution, ${ }^{16}$ medical fees, ${ }^{26}$ the doctor's affiliation with a medical group, ${ }^{26}$ and patient-doctor communication. ${ }^{15,17,27}$

The appeal of DSB is that it is a strategy for coping with medical uncertainty. Alternatively, it is caused by distrust in physicians or the system. By seeking second opinions and making lay consultations, patients hope to understand the prognosis of a disease and to choose an institution for treatment. ${ }^{28}$ This reflects that patients actively participate in the medical care process. Although DSB is regarded as a function of safeguarding against undesirable outcomes from the patient's perspective, limited medical care resources make DSB a stigma among health professionals and policymakers because it causes utility loss, discontinuity of care, and unequal distribution of medical resources.

Most studies on DSB have focused on behaviors occurring either before or immediately after the initial diagnosis. In the former, DSB may occur if a patient's early symptoms cannot be explained or alleviated before the real causes are defined. ${ }^{29}$ Although study designs may vary, a non-life threatening illness may underestimate patients' DSB compared with other critical diseases. A disappointing outcome is one of the most significant reasons for seeking a second opinion. ${ }^{21}$ Especially when addressing malignancy, treatment failure remains the major concern for patients and family. ${ }^{30}$ A research study has yet to address this issue. Prior studies have focused on the initial phase of disease, without a longitudinal follow-up after treatment for cancer. This may limit our understanding of patient behavior, and fail to address the multiple DSB observed in the real world.

To address the gaps in the literature, this pilot study aimed to evaluate the relationship between DSB and treatments and/or results of hepatocellular carcinoma (HCC), a prevailing cancer related to endemic viral hepatitis in Taiwan. According to the Department of Health, hepatitis B carriers presently account for approximately $15 \%$ of the entire population of Taiwan. Annual incidence and mortality rates for $\mathrm{HCC}$ ranked third and second of all malignancies in 2007 and 2009 , respectively. ${ }^{31}$

\section{Materials and methods Data collection}

Between January 2005 and December 2007, a total of 358 cases of HCC (ICD 9 code number 155.0 and 155.2) diagnosed, treated, referred to, or followed up at one study teaching hospital were identified from the in-house cancer registry database. Electronic medical records of 357 patients were reviewed (one record was excluded because of insufficient data) to examine the association between defined factors and the occurrence of DSB. Patients self-referred from outside hospitals were regarded as class 2 patients and other patients were regarded as class 1 patients. The date of the last electronic medical record was July 31, 2010. This study was approved by the appropriate institutional review board (TMUH 01-11-03) and performed accordingly.

\section{Definition of determinants}

When analyzing the hospital electronic medical records for class 2 patients, DSB was recognized as paying visits to other hospitals or transferring from hospital to hospital. In class 1 patients, DSB was regarded as leaving for SO after diagnosis, treatment, and/or during follow-up. In class 2 patients, the number of DSB could be counted according to the transfer note. Nonetheless, for both classes, if a patient left our institution, the information and extent of DSB was recorded as follows: a patient was alive but out of contact with the doctor for more than three months, with no available electronic medical record; patients or families returned for a certificate or medical summary that reported referral institutions; and patients who left but returned to our institution for medical problems other than $\mathrm{HCC}$, and the institutions they had 
visited. The number of DSB (continuous dependent variable) was recorded accordingly. All clinical information retrieved was categorized into three levels of determinants that may affect DSB. Patient determinants consisted of gender, age, marital status, and level of education. Disease determinants were hepatitis profile, family history of malignancy, and/ or hepatitis. Treatment determinants included: recurrence (nominal independent variable), defined as newly developed or persistent intrahepatic lesions requiring locoregional treatment (such as surgery, radiofrequency ablation, percutaneous ethanol injection, transarterial chemoembolization, radiotherapy); progression (nominal independent variable), defined as detection of newly developed extrahepatic metastases, failure of locoregional treatment, and/or initiation of systemic treatments as a salvage strategy or supportive care; upfront first treatment (nominal independent variable), defined as the initial active treatment received by all patients following a cancer diagnosis (Figure 1); salvage treatment (nominal independent variable), defined as the treatment received by patients in recurrent or progressive disease states; and first treatment in-house (nominal independent variable), defined as the first treatment received in the study teaching hospital. Supportive care was not included as treatment in the analysis.

\section{Data analysis}

To evaluate the significance of all determinants in relation to DSB, frequency tables were prepared and the Chi-squared test was applied. After adjusting for the confounding effects of patients and diseases, the associations between treatment determinants and DSB were analyzed based on various hypotheses and tested in multivariate logistic regression models. All $P$-values reported were obtained from two-sided tests. Statistical significance was set at $P<0.05$. All analyses were performed using SAS version 9.2 (SAS Institute Inc, Cary, NC, USA).

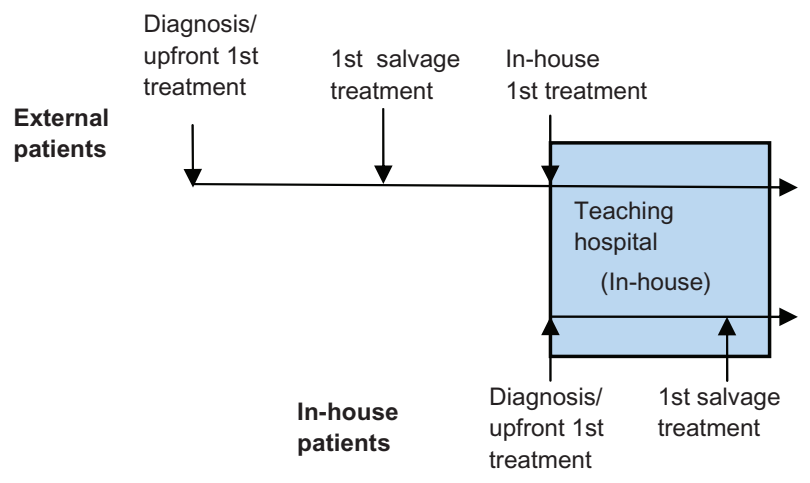

Figure I Treatment at different decision points.

\section{Results \\ Descriptive statistics}

As shown in Table 1, the majority of patients (77.3\%) were middle-aged to elderly. Four fifths were men and 56\% were chronic hepatitis B carriers. Class 1 and class 2 patients accounted for $22.1 \%$ and $77.9 \%$ of all patients, respectively. Married (78.4\%) and poorly educated (51.8\%) patients were the predominant subgroups. History of hepatitis or HCC in the family was noted in $13.4 \%$ of all cases. Among these, $21.5 \%$ of class 1 and $28.8 \%$ of class 2 patients left the study institution and undertook DSB. One third of patients reported

Table I Characteristics of determinants

\begin{tabular}{|c|c|c|}
\hline Variable & $n=357$ & $\%$ \\
\hline \multicolumn{3}{|l|}{ Gender } \\
\hline Male & 286 & 80.1 \\
\hline Female & 71 & 19.9 \\
\hline Mean age (years) & 56 & \\
\hline$<50$ & 81 & 22.7 \\
\hline $5 I-70$ & 190 & 53.2 \\
\hline$>70$ & 86 & 24.1 \\
\hline \multicolumn{3}{|l|}{ Hepatitis } \\
\hline B & 200 & 56.0 \\
\hline C & 82 & 23.0 \\
\hline$B+C$ & 16 & 4.5 \\
\hline None & 44 & 12.3 \\
\hline Unknown & 15 & 4.2 \\
\hline \multicolumn{3}{|l|}{ Marital status } \\
\hline Married & 280 & 78.4 \\
\hline Unmarried & 37 & 10.4 \\
\hline Divorced/widowed & 22 & 6.2 \\
\hline Unknown & 18 & 5.0 \\
\hline \multicolumn{3}{|l|}{ Education } \\
\hline College and above & 52 & 14.6 \\
\hline High school & 71 & 19.9 \\
\hline Middle school & 75 & 21.0 \\
\hline Elementary/illiterate & 110 & 30.8 \\
\hline Unknown & 49 & 13.7 \\
\hline \multicolumn{3}{|l|}{ Family history } \\
\hline None/not known & 288 & 80.7 \\
\hline Hepatitis/HCC & 48 & 13.4 \\
\hline Other cancers & 21 & 5.9 \\
\hline \multicolumn{3}{|l|}{ First institution } \\
\hline In-house (class I) & 79 & 22.1 \\
\hline External (class 2) & 278 & 77.9 \\
\hline \multicolumn{3}{|l|}{ Number of DSB } \\
\hline None & 44 & 12.3 \\
\hline Once & 118 & 33.1 \\
\hline More than once & 195 & 54.6 \\
\hline Progressive disease & 81 & 22.6 \\
\hline Recurrent disease & 130 & 36.4 \\
\hline Upfront first treatment & 306 & 85.7 \\
\hline In-house first treatment & 212 & 59.3 \\
\hline Salvage treatment & 147 & 41.1 \\
\hline
\end{tabular}


DSB once, whereas $54.6 \%$ reported doing so more than once. The three foremost reasons for class 2 patients to visit this teaching hospital were high-technology treatments $(18.7 \%$, eg, cryotherapy, stereotactic radiotherapy, targeted agents), followed by confirmation of diagnosis $(9.0 \%)$ and treatment options $(8.7 \%)$.

\section{Statistical inferences}

The present study hypothesized that patients with recurrent or progressive HCC would be prone to first-time DSB, and patients who accepted their upfront first treatments would have a lower probability of first-time DSB. However, as shown in multivariate analyses (Table 2), disease progression $(P=0.663)$ and receiving of upfront first treatment

Table 2 Characteristics of patients and whether or not conducting first-time doctor-shopping behavior

\begin{tabular}{|c|c|c|c|c|}
\hline \multirow{2}{*}{$\frac{\text { Variables }}{\text { Age, years }}$} & \multirow[t]{2}{*}{ OR } & \multicolumn{2}{|c|}{$95 \% \mathrm{Cl}$} & \multirow[t]{2}{*}{$P$-value } \\
\hline & & & & \\
\hline \multicolumn{5}{|l|}{$($ ref $=<50)$} \\
\hline$>70$ & 0.858 & 0.383 & 10.921 & 0.709 \\
\hline $51-70$ & 1.457 & 0.337 & 60.295 & 0.614 \\
\hline \multicolumn{5}{|l|}{ Gender } \\
\hline \multicolumn{5}{|l|}{$($ ref = female $)$} \\
\hline Male & 1.476 & 0.649 & 30.356 & 0.353 \\
\hline \multicolumn{5}{|l|}{ Education } \\
\hline \multicolumn{5}{|c|}{ (ref = elementary/illiterate) } \\
\hline Middle school & 0.821 & 0.363 & 10.853 & 0.634 \\
\hline High school & 1.219 & 0.487 & 30.053 & 0.673 \\
\hline Above college & 1.039 & 0.358 & 30.010 & 0.945 \\
\hline \multicolumn{5}{|l|}{ Marriage } \\
\hline \multicolumn{5}{|l|}{$($ ref = married $)$} \\
\hline Unmarried & 0.690 & 0.272 & 10.754 & 0.436 \\
\hline Divorced/widowed & 1.615 & 0.408 & 60.395 & 0.495 \\
\hline \multicolumn{5}{|l|}{ Hepatitis } \\
\hline \multicolumn{5}{|l|}{ (ref = negative) } \\
\hline B & 2.532 & 1.040 & 60.164 & $0.04 I$ \\
\hline C & 1.919 & 0.711 & 50.183 & 0.127 \\
\hline$B+C$ & 2.405 & 0.416 & 130.887 & 0.372 \\
\hline \multicolumn{5}{|l|}{ Family history } \\
\hline \multicolumn{5}{|l|}{ (ref = no history) } \\
\hline HCC and/or hepatitis & 1.829 & 0.692 & 40.836 & 0.224 \\
\hline Other cancers & 0.949 & 0.279 & 30.235 & 0.934 \\
\hline \multicolumn{5}{|l|}{ Recurrence } \\
\hline \multicolumn{5}{|l|}{$(\mathrm{ref}=\mathrm{no})$} \\
\hline Yes & 0.411 & 0.205 & 00.824 & 0.012 \\
\hline \multicolumn{5}{|l|}{ Progressive disease } \\
\hline \multicolumn{5}{|l|}{$(\mathrm{ref}=\mathrm{no})$} \\
\hline Yes & 1.188 & 0.548 & 20.576 & 0.663 \\
\hline \multicolumn{5}{|l|}{$\begin{array}{l}\text { Upfront first treatment } \\
\qquad(\text { ref }=\text { no })\end{array}$} \\
\hline Yes & 0.939 & 0.479 & 10.839 & 0.854 \\
\hline
\end{tabular}

Note: Multivariate logistic model, $\mathrm{n}=357$.

Abbreviations: $\mathrm{Cl}$, confidence interval; $\mathrm{HCC}$, hepatocellular carcinoma; OR, odds ratio.
$(P=0.854)$ were not significantly associated with the occurrence of first-time DSB. On the contrary, HCC patients with recurrence were less likely to undertake first-time DBS (odds ratio [OR] 0.411, $P=0.012$ ). Compared with noncarriers, hepatitis B carriers also had a significantly higher probability of first-time DSB (OR 2.532, $P=0.040$ ).

Intuitively, receiving treatment after diagnosis usually implies that a relationship between a physician and patient has been established. This can reduce the likelihood of future DSB. In contrast, avoiding receiving salvage treatment for disease recurrence or progression may increase the likelihood of single or multiple DSB. Therefore, the present study hypothesized that, in class 2 patients, receiving upfront first or first salvage treatment would reduce the number of DSB. In bivariate analysis, both upfront first treatment and first salvage treatment were significantly associated with the amount of DSB (once versus more than once). However, logistic model analysis identified that only patients not receiving upfront first treatment undertook multiple DSB (OR 0.435, $P=0.029$, Table 3). In 107 (38.48\%) class 2 patients with progression and/or recurrence who were eligible for first salvage treatment, subgroup reanalysis showed that receiving upfront first treatment or first salvage treatment did not significantly influence the extent of DSB $(P=0.921$ and 0.983 , respectively, Table 4). Among these patients, men were less likely to show DSB on more than one occasion than their female counterparts (OR 0.026, $P=0.010$ ).

When physicians recommended a new in-house treatment, all patients had to decide whether to stay with or leave the study institution (Figure 1, shaded box). The treatment may or may not have been appropriate for their condition or fulfilled their needs. Hence, the present study hypothesized that, at this stage, new DSB may relate to rejection of the treatment suggestion. As determined in bivariate analysis, first in-house treatment, age $<50$ years, and recurrence were significantly associated with patient decision-making. However, among these factors, more elderly (age $>70$ years) patients were likely to stay with the study hospital (OR 0.270, $P=0.022$, Table 5) than younger (age $<50$ years) patients. Similarly, patients receiving their first in-house treatment were more likely to remain at the study hospital, but this was of borderline significance (OR 0.593, $P=0.066$, Table 5).

\section{Discussion}

The health care system in Taiwan places no restrictions on patient DSB, ${ }^{32,33}$ allowing free access to all institutions and specialists. Although previous research on DSB is limited, studies have identified a number of associated factors, with 
Table 3 Characteristics of class 2 patients and extent of doctorshopping behavior at outside hospitals

\begin{tabular}{|c|c|c|c|c|}
\hline \multirow{2}{*}{$\frac{\text { Variables }}{\text { Age, years }}$} & \multirow[t]{2}{*}{ OR } & \multicolumn{2}{|l|}{$95 \% \mathrm{Cl}$} & \multirow[t]{2}{*}{$P$-value } \\
\hline & & & & \\
\hline \multicolumn{5}{|l|}{$($ ref $=<50)$} \\
\hline $5 \mathrm{I}-70$ & 0.967 & 0.442 & 2.115 & 0.932 \\
\hline$>70$ & 0.502 & 0.125 & 2.018 & 0.331 \\
\hline \multicolumn{5}{|l|}{ Gender } \\
\hline \multicolumn{5}{|l|}{$($ ref = female $)$} \\
\hline Male & 0.441 & 0.186 & 1.042 & 0.062 \\
\hline \multicolumn{5}{|l|}{ Education } \\
\hline \multicolumn{5}{|c|}{ (ref = elementary/illiterate) } \\
\hline Middle school & 0.614 & 0.249 & 1.514 & 0.290 \\
\hline High school & 0.953 & 0.415 & 2.185 & 0.909 \\
\hline Above college & 1.771 & 0.684 & 4.585 & 0.239 \\
\hline \multicolumn{5}{|l|}{ Marriage } \\
\hline \multicolumn{5}{|l|}{$($ ref = married $)$} \\
\hline Unmarried & 1.267 & 0.454 & 3.536 & 0.652 \\
\hline Divorced/widowed & 0.304 & 0.073 & 1.274 & 0.103 \\
\hline \multicolumn{5}{|l|}{ Hepatitis } \\
\hline \multicolumn{5}{|l|}{ (ref = negative) } \\
\hline B & 1.174 & 0.424 & 3.255 & 0.758 \\
\hline C & 0.720 & 0.222 & 2.336 & 0.585 \\
\hline$B+C$ & 0.787 & 0.122 & 5.067 & 0.801 \\
\hline \multicolumn{5}{|l|}{ Family history } \\
\hline \multicolumn{5}{|l|}{ (ref = no history) } \\
\hline HCC and/or hepatitis & 0.631 & 0.283 & 1.410 & 0.262 \\
\hline Other cancers & 0.744 & 0.209 & 2.648 & 0.648 \\
\hline \multicolumn{5}{|l|}{ Recurrence } \\
\hline \multicolumn{5}{|l|}{$($ ref $=$ no $)$} \\
\hline Yes & 1.033 & 0.518 & 2.063 & 0.926 \\
\hline \multicolumn{5}{|l|}{ Progressive disease } \\
\hline \multicolumn{5}{|l|}{$(\mathrm{ref}=\mathrm{no})$} \\
\hline Yes & 1.427 & 0.660 & 3.087 & 0.366 \\
\hline \multicolumn{5}{|l|}{$\begin{array}{l}\text { Upfront first treatment } \\
\qquad(\text { ref }=\text { no })\end{array}$} \\
\hline Yes & 0.435 & 0.206 & 0.918 & 0.029 \\
\hline
\end{tabular}

Notes: Once versus more than once, multivariate logistic model, $n=278$.

Abbreviations: $\mathrm{Cl}$, confidence interval; $\mathrm{HCC}$, hepatocellular carcinoma; OR, odds ratio.

treatments and outcomes remaining the major concerns for patients. Therefore, disease recurrence or progression, and patients' failure to receive timely treatment, may be potentially associated with DSB. However, electronic medical records do not provide information on treatment planning discussions during the physician-patient encounter. Therefore, receiving treatment was a proxy indicator of patients' agreement with the recommended treatment and choice to stay with the provider. In addition to the usual reasons for seeking second opinions, as identified in an Australian study, ${ }^{34}$ the present series also revealed distinct seeking of high-technology treatment options as a reason for DSB.

Unlike other malignancies, primary HCC usually requires multiple cycles of locoregional treatment. Disease progression
Table 4 Characteristics of class 2 patients* and extent of doctorshopping behavior at outside hospitals

\begin{tabular}{|c|c|c|c|c|}
\hline Variables & \multirow[t]{2}{*}{ OR } & \multicolumn{2}{|l|}{$95 \% \mathrm{Cl}$} & \multirow[t]{2}{*}{$P$-value } \\
\hline \multirow{2}{*}{\multicolumn{5}{|c|}{$\begin{array}{l}\text { Age, years } \\
\qquad(\text { ref }=<50)\end{array}$}} \\
\hline & & & & \\
\hline $5 \mathrm{I}-70$ & 0.244 & 0.016 & 30.698 & 0.309 \\
\hline$>70$ & $<0.001$ & $<0.001$ & $>9990.999$ & 0.939 \\
\hline \multicolumn{5}{|l|}{ Gender } \\
\hline \multicolumn{5}{|l|}{$($ ref = female $)$} \\
\hline Male & 0.026 & 0.002 & 0.422 & 0.010 \\
\hline \multicolumn{5}{|l|}{ Education } \\
\hline \multicolumn{5}{|c|}{ (ref = elementary/illiterate) } \\
\hline Middle school & 0.013 & $<0.001$ & 0.601 & 0.027 \\
\hline High school & 0.138 & 0.009 & 10.999 & 0.146 \\
\hline Above college & 0.111 & 0.004 & 20.956 & 0.190 \\
\hline \multicolumn{5}{|l|}{ Marriage } \\
\hline \multicolumn{5}{|l|}{ (ref = married) } \\
\hline Unmarried & 0.093 & 0.002 & 30.842 & 0.211 \\
\hline Divorced/widowed & 0.021 & $<0.001$ & 10.694 & 0.085 \\
\hline \multicolumn{5}{|l|}{ Hepatitis } \\
\hline \multicolumn{5}{|l|}{ (ref = negative) } \\
\hline B & 1.051 & 0.051 & 210.752 & 0.974 \\
\hline C & 0.042 & $<0.001$ & 40.022 & 0.173 \\
\hline$B+C$ & 158.927 & 0.527 & $>9990.999$ & 0.082 \\
\hline \multicolumn{5}{|l|}{ Family history } \\
\hline \multicolumn{5}{|l|}{ (ref = no history) } \\
\hline HCC and/or hepatitis & 0.174 & 0.012 & 20.543 & 0.201 \\
\hline Other cancers & 3.431 & 0.230 & 510.089 & 0.371 \\
\hline \multicolumn{5}{|l|}{ Recurrence } \\
\hline \multicolumn{5}{|l|}{$(\mathrm{ref}=\mathrm{no})$} \\
\hline Yes & 0.177 & 0.016 & 10.947 & 0.157 \\
\hline \multirow{2}{*}{\multicolumn{5}{|c|}{$\begin{array}{l}\text { Progressive disease } \\
\qquad(\text { ref }=\text { no })\end{array}$}} \\
\hline & & & & \\
\hline Yes & 4.402 & 0.791 & 240.485 & 0.091 \\
\hline \multirow{2}{*}{\multicolumn{5}{|c|}{$\begin{array}{l}\text { Upfront first treatment } \\
(r \text { ref }=\text { no })\end{array}$}} \\
\hline & & & & \\
\hline Yes & $<0.001$ & $<0.001$ & $>9990.999$ & 0.921 \\
\hline \multicolumn{5}{|l|}{$\begin{array}{l}\text { First salvage treatment } \\
\qquad(\mathrm{ref}=\mathrm{no})\end{array}$} \\
\hline Yes & 0.966 & 0.042 & 220.383 & 0.983 \\
\hline
\end{tabular}

Notes: *Progression and/or recurrence eligible for first salvage treatment. Once versus more than once, multivariate logistic model, $n=107$.

Abbreviations: $\mathrm{Cl}$, confidence interval; $\mathrm{HCC}$, hepatocellular carcinoma; $\mathrm{OR}$, odds ratio.

represents a more severely worsening condition than recurrence. Recurrence and progression of HCC may cause loss of confidence in physicians and a strong tendency toward DSB. This reflects the fact that, irrespective of how unrealistic expectations may be, most patients accept any treatment, even if the chances of benefit are minimal. ${ }^{35}$ Analyses in the present study did not identify any effects of progression on DSB. This may be due to the complex causes of death from liver cirrhosis, which may predate and negate the influence of progression. Contradictory to our hypothesis, recurrence was significantly less likely to be associated with first-time DSB. 
Table $\mathbf{5}$ Characteristics of patients and whether they stay at or leave the study hospital

\begin{tabular}{|c|c|c|c|c|}
\hline \multirow{2}{*}{$\frac{\text { Variables }}{\text { Age, years }}$} & \multirow[t]{2}{*}{ OR } & \multicolumn{2}{|l|}{$95 \% \mathrm{Cl}$} & \multirow[t]{2}{*}{$P$-value } \\
\hline & & & & \\
\hline \multicolumn{5}{|l|}{$($ ref $=<50)$} \\
\hline $5 I-70$ & 0.850 & 0.456 & 1.583 & 0.609 \\
\hline$>70$ & 0.270 & 0.088 & 0.830 & 0.022 \\
\hline \multicolumn{5}{|l|}{ Gender } \\
\hline \multicolumn{5}{|l|}{ (ref = female) } \\
\hline Male & 1.255 & 0.626 & 2.397 & 0.553 \\
\hline \multicolumn{5}{|l|}{ Education } \\
\hline \multicolumn{5}{|c|}{$($ ref $=$ elementary/illiterate $)$} \\
\hline Middle school & 0.712 & 0.363 & 1.394 & 0.321 \\
\hline High school & 0.846 & 0.432 & 1.656 & 0.625 \\
\hline Above college & 1.862 & 0.846 & 4.098 & 0.122 \\
\hline \multicolumn{5}{|l|}{ Marriage } \\
\hline \multicolumn{5}{|l|}{$($ ref $=$ married $)$} \\
\hline Unmarried & 1.045 & 0.477 & 2.290 & 0.912 \\
\hline Divorced/widowed & 0.622 & 0.209 & 1.856 & 0.395 \\
\hline \multicolumn{5}{|l|}{ Hepatitis } \\
\hline \multicolumn{5}{|l|}{ (ref = negative) } \\
\hline B & 1.407 & 0.639 & 3.097 & 0.397 \\
\hline $\mathrm{C}$ & 2.173 & 0.895 & 5.278 & 0.086 \\
\hline$B+C$ & 1.428 & 0.360 & 5.655 & 0.612 \\
\hline \multicolumn{5}{|l|}{ Family history } \\
\hline \multicolumn{5}{|l|}{ (ref = no history) } \\
\hline HCC and/or hepatitis & 0.842 & 0.438 & 1.617 & 0.606 \\
\hline Other cancers & 1.187 & 0.455 & 3.096 & 0.726 \\
\hline \multicolumn{5}{|l|}{ Recurrence } \\
\hline \multicolumn{5}{|l|}{$(\mathrm{ref}=\mathrm{no})$} \\
\hline Yes & 0.703 & 0.397 & 1.245 & 0.227 \\
\hline \multicolumn{5}{|l|}{ Progressive disease } \\
\hline \multicolumn{5}{|l|}{$(\mathrm{ref}=\mathrm{no})$} \\
\hline Yes & 0.861 & 0.470 & 1.576 & 0.627 \\
\hline \multicolumn{5}{|l|}{$\begin{array}{l}\text { First in-house treatment } \\
\qquad(\mathrm{ref}=\mathrm{no})\end{array}$} \\
\hline Yes & 0.593 & 0.339 & 1.036 & 0.066 \\
\hline
\end{tabular}

Note: Multivariate logistic model, $n=357$.

Abbreviations: $\mathrm{Cl}$, confidence interval; $\mathrm{HCC}$, hepatocellular carcinoma; $\mathrm{OR}$, odds ratio.

A possible explanation for this may be that patients had already done their DSB for surgical or diagnostic purposes prior to the occurrence and influence of true disease recurrence. In reality, not only differences in cultures and health care systems may influence causes of DSB, but research in different settings may also occasionally yield results contradictory to existing knowledge about DSB. Considering the series reported by Mellink et al as an example, negative experiences and dissatisfaction might not lead to motivation to seek second opinions. ${ }^{36}$ Among hepatitis carriers, hepatitis B status was an independent factor significantly related to DSB. Patients showing firsttime DSB were significantly more likely to be hepatitis B carriers than noncarriers. Possible reasons for this include high patient awareness of the endemic and an abundance of hepatitis B-related social campaigns in society.
The present study hypothesized that more upfront first treatments received by patients is indicative of a lower probability of first-time DSB. However, whole group analysis was unable to show this influence. In subgroup analysis, class 2 patients receiving more upfront first treatments were significantly less likely to show multiple DSB. This was especially true in a number of class 2 patients who sought expert opinions (first DSB) prior to making treatment decisions. Once they had decided to receive treatment, they were less likely to leave for another or multiple opinions. An explanation for why men were significantly less inclined to undertake multiple DSB than women has yet to be identified.

According to a survey often cited by physicians, requests for more treatments account for nearly half the reasons for patients seeking a second opinion. ${ }^{37}$ Therefore, during examination of the effects of in-house treatment on decisions to leave or stay with the study hospital, receiving treatment was a proxy indicator of patient compliance, and reasonably inferred patients' decisions to stay. In multivariate analyses, none of the factors were significant, except for elderly patients ( $>70$ years), who were more likely than younger patients to stay with rather than leave the study hospital.

In some Western series, older adults have been shown to be much more trusting of their physicians and less likely to seek second opinions..$^{38}$ If patients trust their physicians, satisfaction increases with age..$^{39}$ This implies DSB may occur less frequently, even without direct measurement, if trust exists. Therefore, trust may be a proxy for DSB. However, it is a construct of various definitions that distrust may lead to subsequent disenrollment, switching physicians or institutions, poor loyalty, and nonadherence. ${ }^{40}$ Nevertheless, the role that trust plays in DSB is never simple to understand and measure, with so many theories and limited data available. Previous research has also yielded conflicting results concerning whether age has an impact on trust. ${ }^{41}$ More importantly, different cancer types have their own age predilections in incidence, in which age can have a significant or nonsignificant effect on DSB. The only way to delineate how age affects DSB is to use a larger study series focusing on how age influences commitment to a physician or institution and how trust develops and evolves.

Another explanation for the age factor may relate to patient infirmity, such that supportive care is always the preference of patients and/or physicians. In other words, poor physical performance may limit patient opportunities to seek other opinions. Other possible explanations for the lack of effects of other factors on DSB include the late stage of some heavily pretreated patients, and/or the occurrence 
of acute life threatening events (such as esophageal varices bleeding, encephalopathy), which allow patients no other option than to stay for supportive care before succumbing to the disease. In light of all these results, we believe ours is the first study to correlate disease status and treatments with $\mathrm{DSB}$, an intuitive association that has rarely been verified in previous studies.

DSB occasionally escapes notice until loss of the patient from regular follow-up. Any single model theory cannot explain the sporadic occurrence of DSB during a long dynamic process. Previous studies have investigated factors associated with DSB in patients at initial diagnosis or in the early phase of treatment. For cancer, the entire treatment course can be complicated by patient disease status, psychological reactions, and family attitudes. The patients are also in a constant state of change because of experiences with treatment and interactions with health professionals other than oncologists. Patients and their families usually monitor outcomes and may question the physician's competence. ${ }^{42}$ Therefore, the relationship between patient and physician is neither stable nor indefinite, rationalizing DSB when patients feel insecure or are uncomfortable with the results of treatment. In an analysis of the characteristics of patients with DSB, Tattersall et al observed that those presenting to cancer outpatient clinics were generally more highly educated breast cancer patients working in managerial or professional positions. ${ }^{34}$ However, the characteristics of patients investigated in their study do not apply to the HCC patients in our present study. This reflects not only the uniqueness of patients, but also the fact that different study designs may have varying interpretations.

Increasing patient expectations from health care and increased accessibility to SO may result in increasing numbers of patients seeking these. ${ }^{3,43}$ This is especially true in the era of the Internet, at a minimal rate of $10 \%-44 \%,{ }^{44,45}$ and in any health care system without a "gatekeeper". In oncology, single or multiple DSB are likely to occur frequently because of the life threatening nature of a disease and the toxic treatment modalities often used. Regardless, investigators have suggested that physicians can and should take measures to prevent a proportion of second opinions, or at least some of the patients' unrealistic expectations. ${ }^{30,46}$ A nationwide hepatitis surveillance program initiated by the Bureau of National Health Insurance in 2011 is designed to follow up carriers to balance the advantages and disadvantages of DSB. This program promotes periodic surveillance and continuity of care in the hope of early detection and intervention. To reduce the costs incurred by patient DSB, this program also rewards physician-initiated referral. This can consolidate the patient-physician relationship by enhancing the level of trust between both parties, and can also facilitate effective communication of a treatment plan after a diagnosis of HCC. Even for patients who wish to be referred to another physician, this patient-centered approach will help physicians to respect patient preferences rather than act in an authoritarian manner.

However, people generally hold the fundamental belief that they have the right to knowledge, information, and control over management decisions. Based on this argument, it is the patient's right to seek an SO if this empowers them to make appropriate decisions. This holds true in the era of consumerism, patient autonomy, empowerment, and the Internet. Generally, as suggested by Barsky, ${ }^{47}$ seeking SO is a social phenomenon and DSB is for reimbursement purposes (Second Surgical Opinion Programs, US), ${ }^{48}$ and all other possible ethical and legal issues ${ }^{49,50}$ may ensue. Sato et al suggested that $\mathrm{SO}$ once is more of an acceptable behavior than DSB more than once, which may give an impression of abusing medical resources. ${ }^{27}$

DSB may occasionally imply a negative experience for both patients and providers, and may be perceived as distrust or dissatisfaction with the services provided. However, the patient's health remains his/her (and the oncologist's) primary consideration. As described by Axon et al, numerous differing viewpoints exist in medicine; no one is infallible, and professional arrogance has no part to play. ${ }^{51}$ Appropriate perspectives on the part of the institution and its physicians toward SO and DSB may include respect for the patient's preferences, attitudes, and decisions for DSB; DSB provides the opportunity to re-evaluate the treatment offered, which may not be of the highest standard, to maximize its benefits and avoid legal issues, and to involve the patient and caretakers in a shared decision-making process throughout the course of the disease.

In conclusion, the findings of the present study indicate that recurrence is less likely to be associated with first-time DSB, and that hepatitis B carriers are more likely to show first-time DSB than noncarriers. Self-referred patients who received upfront first treatment were less likely to undertake multiple DSB than those who did not. This was especially true for male patients. Patients who did not accept upfront treatment tended to seek multiple opinions throughout the entire treatment course. Receiving first salvage treatment had no effect on the number of DSBs in self-referred patients.

This study has a number of limitations, including: limited external validity and under-representation based on a single institutional experience; the cutoff date of the last follow-up 
may have missed some DSB information from the entire patient course; the sample size for analysis was not large enough to accommodate other variables that may contribute to DSB, such as chronic illness, comorbidities, psychosomatic problems, geographic convenience, and high-technology treatments; and lack of real information on physician-patient encounters and the decision-making process. Numerous studies have demonstrated that patient-physician communication has a significant influence on patient health outcomes. ${ }^{51-54}$ However, many social and cultural backgrounds relevant to this relationship differ between countries. ${ }^{55}$ In the case of life threatening cancer, communication may have a strong impact on patient outcome. ${ }^{56,57}$ Uncertainty and anxiety on the part of the patient and their family may place greater demands on the relationship. ${ }^{58,59}$ Under these circumstances, the content of communication may act as a mediating factor leading to DSB. Further investigation of such factors and their association with DSB is warranted.

\section{Conclusion}

The present study is a person-based longitudinal retrospective analysis using ambulatory and inpatient electronic medical records for patients with $\mathrm{HCC}$. The results demonstrate that DSB can occur during the entire course of treatment, even in patients with severe conditions. This is the first research to evaluate the effects of treatment at different time points, and the subsequent influence on patient DSB. The study also identifies factors contributing to multiple DSB in HCC patients. In 2008, the Bureau of Health Promotion launched a nationwide cancer center accreditation program, which might foster improvement in cancer management and quality of care. Further study is required to understand any changes in DSB following implementation of this program.

\section{Disclosure}

The authors report no conflicts of interest in this work.

\section{References}

1. Moumjid N, Gafni A, Bremond A, Carrere MO. Seeking a second opinion: do patients need a second opinion when practice guidelines exist? Health Policy. 2007;80(1):43-50.

2. Sutherland LR, Verhoef MJ. Patients who seek a second opinion: are they different from the typical referral? J Clin Gastroenterol. 1989;11(3): 308-313.

3. Sutherland LR, Verhoef MJ. Why do patients seek a second opinion or alternative medicine? J Clin Gastroenterol. 1994;19(3):194-197.

4. Wagner TH, Wagner LS. Who gets second opinions? Health Aff (Millwood). 1999;18(5):137-145.

5. Frei A. Second opinion in Switzerland. Design of program and evaluation study. Swiss Surg. 1996;2(4):145-147.

6. Hempel K, Siewert JR. "Second opinion" - attempt at establishing a definition. Chirurg. 1996;67(4):293-296. German.
7. Hempel K, Weissauer W. The "second opinion". Chirurg. 1990; 61(2):Suppl 19-20. German.

8. Weissauer W. The "second opinion". Chirurg. 1990;61(2):Suppl 16-19. German.

9. Vecchio Good M-J, Good B, Schaffer C, Lind S. American oncology and the discourse on hope. Cult Med Psychiatry. 1990;14(1): $59-79$.

10. Long SO. The ins and outs of doctor-patient relations in Japan. Am J Chin Med. 1980;8(1-2):37-46.

11. Ricko Yajima KT. The Japanese health care system: citizen complaints, citizen possibilities. J Health Hum Serv Adm. 1998;20(4):502-519.

12. Chen T-J, Chou L-F, Hwang S-J. Patterns of ambulatory care utilization in Taiwan. BMC Health Serv Res. 2006;6(1):54.

13. Graugaard PK, Eide H, Finset A. Interaction analysis of physicianpatient communication: the influence of trait anxiety on communication and outcome. Patient Educ Couns. 2003;49(2):149-156.

14. Harris KM. How do patients choose physicians? Evidence from a national survey of enrollees in employment-related health plans. Health Serv Res. 2003;38(2):711-732.

15. Guo Y, Kuroki T, Yamashiro S, Koizumi S. Illness behaviour and patient satisfaction as correlates of self-referral in Japan. Fam Pract. 2002;19(4):326-332.

16. Billinghurst $B$, Whitfield $M$. Why do patients change their general practitioner? A postal questionnaire study of patients in Avon. $\mathrm{Br} J$ Gen Pract. 1993;43(373):336-338.

17. Sato T, Takeichi M, Shirahama M, Fukui T, Gude JK. Doctor-shopping patients and users of alternative medicine among Japanese primary care patients. Gen Hosp Psychiatry. 1995;17(2):115-125.

18. Lobb EA, Kenny DT, Butow PN, Tattersall MH. Women's preferences for discussion of prognosis in early breast cancer. Health Expect. 2001;4(1):48-57.

19. Bayliss R. Second opinions. BMJ. 1988;296(6625):808-809.

20. Sapir R, Catane R, Kaufman B, et al. Cancer patient expectations of and communication with oncologists and oncology nurses: the experience of an integrated oncology and palliative care service. Support Care Cancer. 2000;8(6):458-463.

21. van Dalen I, Groothoff J, Stewart R, Spreeuwenberg P, Groenewegen P, van Horn J. Motives for seeking a second opinion in orthopaedic surgery. J Health Serv Res Policy. 2001;6(4):195-201.

22. Thomas K, Nicholl J, Coleman P. Assessing the outcome of making it easier for patients to change general practitioner: practice characteristics associated with patient movements. Br J Gen Pract. 1995;45(400): 581-586.

23. Tam KF, Cheng DK, Ng TY, Ngan HY. The behaviors of seeking a second opinion from other health-care professionals and the utilization of complementary and alternative medicine in gynecologic cancer patients. Support Care Cancer. 2005;13(9):679-684.

24. Bornstein BH, Marcus D, Cassidy W. Choosing a doctor: an exploratory study of factors influencing patients' choice of a primary care doctor. J Eval Clin Pract. 2000;6(3):255-262.

25. Gandhi IG, Parle JV, Greenfield SM, Gould S. A qualitative investigation into why patients change their GPs. Fam Pract. 1997;14(1):49-57.

26. Wolinsky FD, Steiber SR. Salient issues in choosing a new doctor. Soc Sci Med. 1982;16(7):759-767.

27. Sato T, Takeichi M, Hara T, Koizumi S. Second opinion behaviour among Japanese primary care patients. Br J Gen Pract. 1999;49(444): 546-550.

28. Chiang H-C. The second-opinion behavior in doctor-seeking process in Taiwan. Master's thesis. Taiwan, People's Republic of China: Institute of Health Policy and Management, College of Public Health, National Taiwan University; 2006.

29. Chang L-Y. The logic of care seeking. Taiwanese Journal of Sociology. 1998;21:59-87.

30. Sikora K. Second opinions for patients with cancer. BMJ. 1995;311(7014): 1179-1180.

31. Department of Health, Taiwan [homepage on the Internet]. Health Information for the public. Available from: http://www.doh.gov.tw/ EN2006/index_EN.aspx. Accessed November 28, 2011. 
32. Wang MJ, Lin SP. Study on doctor shopping behavior: insight from patients with upper respiratory tract infection in Taiwan. Health Policy. 2010;94(1):61-67.

33. Chou L, Chen TJ. Relationship of doctor shopping and polypharmacy: a nationwide study in Taiwan Presented at the 13th Annual International Meeting of the International Society for Pharmacoeconomics, Toronto, ON, Canada, May 3-7, 2008.

34. Tattersall MH, Dear RF, Jansen J, et al. Second opinions in oncology: the experiences of patients attending the Sydney Cancer Centre. Med J Aust. 2009;191(4):209-212.

35. Slevin ML, Stubbs L, Plant HJ, et al. Attitudes to chemotherapy: comparing views of patients with cancer with those of doctors, nurses, and general public. BMJ. 1990;300(6737):1458-1460.

36. Mellink WA, Dulmen AM, Wiggers T, Spreeuwenberg PM, Eggermont AM, Bensing JM. Cancer patients seeking a second surgical opinion: results of a study on motives, needs, and expectations. J Clin Oncol. 2003;21(8):1492-1497.

37. Philip J, Gold M, Schwarz M, Komesaroff P. Second medical opinions: the views of oncology patients and their physicians. Support Care Cancer. 2010;18(9):1199-1205.

38. Greene MG, Adelman RD, Friedmann E, Charon R. Older patient satisfaction with communication during an initial medical encounter. Soc Sci Med. 1994;38(9):1279-1288.

39. Thom DH, Ribisl KM, Stewart AL, Luke DA, Physicians TSTS. Further validation and reliability testing of the Trust in Physician Scale. Med Care. 1999;37(5):510-517.

40. Adelman RD, Greene MG, Ory MG. Communication between older patients with their physicians. Clin Geriatr Med. 2000;16(1):1-17.

41. Keating NL, Gandhi TK, Orav EJ, Bates DW, Ayanian JZ. Patient characteristics and experiences associated with trust in specialist physicians. Arch Intern Med. 2004;164(9):1015-1020.

42. Roberge D, Beaulieu MD, Haddad S, Lebeau R, Pineault R. Loyalty to the regular care provider: patients' and physicians' views. Fam Pract. 2001;18(1):53-59.

43. Zimmerman TJ. Second opinions in ophthalmic health care. Arch Ophthalmol. 1990;108(2):192-194.

44. Basch EM, Thaler HT, Shi W, Yakren S, Schrag D. Use of information resources by patients with cancer and their companions. Cancer. 2004;100(11):2476-2483.

45. Helft PR, Eckles RE, Johnson-Calley CS, Daugherty CK. Use of the Internet to obtain cancer information among cancer patients at an urban county hospital. J Clin Oncol. 2005;23(22):4954-4962.

46. Macdonald EA. Second opinions in oncology: nuisance or opportunity? Clin Oncol. 1997;9(6):418-420.
47. Barsky AJ. The paradox of health. $N$ Engl J Med. 1988;318(7): 414-418.

48. The official US government site for Medicare [homepage on the Internet]. Available from: http://www.medicare.gov/what-medicare-covers/ part-b/second-opinions-before-surgery.html. Accessed May 30, 2013.

49. Axon A, Hassan M, Niv Y, Beglinger C, Rokkas T. Ethical and legal implications in seeking and providing a second medical opinion. Dig Dis. 2008;26(1):11-17.

50. Gertman PM, Stackpole DA, Levenson DK, Manuel BM, Brennan RJ, Janko GM. Second opinions for elective surgery. The mandatory Medicaid program in Massachusetts. N Engl J Med. 1980;302(21): 1169-1174.

51. Ong LM, de Haes JC, Hoos AM, Lammes FB. Doctor-patient communication: a review of the literature. Soc Sci Med. 1995;40(7): 903-918.

52. Ishikawa H, Takayama T, Yamazaki Y, Seki Y, Katsumata N, Aoki Y. The interaction between physician and patient communication behaviors in Japanese cancer consultations and the influence of personal and consultation characteristics. Patient Educ Couns. 2002;46(4):277-285.

53. Zolnierek KB, Dimatteo MR. Physician communication and patient adherence to treatment: a meta-analysis. Med Care. 2009;47(8): 826-834.

54. Beck RS, Daughtridge R, Sloane PD. Physician-patient communication in the primary care office: a systematic review. J Am Board Fam Pract. 2002;15(1):25-38.

55. Nilchaikovit T, Hill JM, Holland JC. The effects of culture on illness behavior and medical care: Asian and American differences. Gen Hosp Psychiatry. 1993;15(1):41-50.

56. Brédart A, Bouleuc C, Dolbeault S. Doctor-patient communication and satisfaction with care in oncology. Curr Opin Oncol. 2005;17(4): 351-354.

57. Zachariae R, Pedersen CG, Jensen AB, Ehrnrooth E, Rossen PB, von der Maase H. Association of perceived physician communication style with patient satisfaction, distress, cancer-related self-efficacy, and perceived control over the disease. Br J Cancer. 2003;88(5):658-665.

58. Ben-Sira Z. Affective and instrumental components in the physicianpatient relationship: an additional dimension of interaction theory. $J$ Health Soc Behav. 1980;21(2):170-180.

59. Molleman E, Krabbendam PJ, Annyas AA, Koops HS, Sleijfer DT, Vermey A. The significance of the doctor-patient relationship in coping with cancer. Soc Sci Med. 1984;18(6):475-480.
Patient Preference and Adherence

\section{Publish your work in this journal}

Patient Preference and Adherence is an international, peer-reviewed, open access journal focusing on the growing importance of patient preference and adherence throughout the therapeutic continuum. Patient satisfaction, acceptability, quality of life, compliance, persistence and their role in developing new therapeutic modalities and compounds to

\section{Dovepress}

optimize clinical outcomes for existing disease states are major areas of interest. This journal has been accepted for indexing on PubMed Central. The manuscript management system is completely online and includes a very quick and fair peer-review system. Visit http://www.dovepress.com/ testimonials.php to read real quotes from published authors. 